\title{
Adrenal Tumors with Unexpected Outcome: A Review of the Literature
}

\author{
Thomas M. Kerkhofs, ${ }^{1}$ Rudi M. Roumen, ${ }^{2,3}$ Thomas B. Demeyere, ${ }^{4}$ \\ Antoine N. van der Linden, ${ }^{5}$ and Harm R. Haak ${ }^{1,6,7}$ \\ ${ }^{1}$ Department of Internal Medicine, Máxima Medical Center, Ds. Th. Fliednerstraat 1, 5631 BM Eindhoven, The Netherlands \\ ${ }^{2}$ Department of Surgery, Máxima Medical Center, De Run 4600, 5504 DB Veldhoven, The Netherlands \\ ${ }^{3}$ Research School GROW, School for Oncology and Developmental Biology, Maastricht University Medical Centre, P.O. Box 616, \\ 6200 MD Maastricht, The Netherlands \\ ${ }^{4}$ Department of Pathology, Stichting PAMM, Michelangelolaan 2, 5623 EJ Eindhoven, The Netherlands \\ ${ }^{5}$ Department of Radiology, Máxima Medical Center, De Run 4600, 5504 DB Veldhoven, The Netherlands \\ ${ }^{6}$ Department of Internal Medicine, Division of General Internal Medicine, Maastricht University Medical Centre, P.O. Box 5800, \\ 6202 AZ Maastricht, The Netherlands \\ ${ }^{7}$ Department of Health Services Research and CAPHRI School for Public Health and Primary Care, Maastricht University Medical \\ Centre, P.O. Box 616, 6200 MD Maastricht, The Netherlands
}

Correspondence should be addressed to Thomas M. Kerkhofs; t.kerkhofs@mmc.nl

Received 3 August 2014; Revised 1 October 2014; Accepted 1 October 2014

Academic Editor: Claudio Letizia

Copyright (c) 2015 Thomas M. Kerkhofs et al. This is an open access article distributed under the Creative Commons Attribution License, which permits unrestricted use, distribution, and reproduction in any medium, provided the original work is properly cited.

The finding of an adrenal mass should induce a diagnostic work-up aimed at assessing autonomous hormone production and differentiating between benign and (potentially) malignant lesions. The common differential diagnosis in adrenal incidentaloma consists of (non-)functioning adenoma, pheochromocytoma, myelolipoma, metastasis, and primary carcinoma. There remains a category of lesions that are hormonally inactive and display nonspecific imaging characteristics. We provide a succinct literature review regarding pathologies from this category. Imaging and histological characteristics are discussed, as well as clinical management. In conclusion, an adrenal mass may present a diagnostic challenge. After exclusion of most common diagnoses, it can be difficult to differentiate between possible pathologies based on preoperative diagnostic tests. Surgical resection of possibly harmful tumors is indicated, for example, lesions with malignant potential or risk of spontaneous hemorrhage. Resection of an obviously benign lesion is not necessary, unless problems due to tumor size are expected.

\section{Introduction}

Clinicians may be confronted with adrenal masses in four different scenarios. The first category comprises patients presenting with endocrinological symptoms suggesting adrenal origin, such as virilization or Cushing's syndrome as seen in selected adrenocortical adenomas and carcinomas. Hypertension, flushes, and headache may be signs of pheochromocytoma or aldosterone-producing adenoma (Conn's syndrome). Secondly, patients may present with nonspecific symptoms that turn out to be caused by an adrenal tumor such as pain, fatigue, weight loss, or the sensation of an abdominal mass. Thirdly, adrenal metastases might be found in the work-up of another malignancy, for example, lung cancer. Finally, an adrenal mass may be found incidentally during evaluation for nonrelated complaints: a so-called adrenal incidentaloma.

The common differential diagnosis includes six entities which account for the large majority of all adrenal masses. This will be discussed first. Secondly, we discuss a remaining category that consists of ten entities that are hormonally inactive and display nonspecific imaging characteristics. 


\section{Differential Diagnosis}

The common differential diagnosis in adrenal incidentaloma consists of nonfunctioning adenoma, functioning adenoma, pheochromocytoma, and adrenocortical carcinoma. Myelolipomas and metastases from various malignancies are also common and should be included $[1,2]$. The ranking by likelihood of these diagnoses varies depending on individual presentation. In general, most incidentalomas (70-80\%) are benign adenomas which cause no symptoms. However, in 5-20\% of patients who have no endocrine signs or symptoms, analysis reveals subclinical hypercortisolism [3-5]. Pheochromocytoma makes up about $1.5-14 \%$ of incidentalomas, adrenocortical carcinoma (ACC) is found in 1.2$11 \%$, aldosterone-producing adenoma is found in $1.6-3.3 \%$, and adrenal metastases are found in $1-18 \%[6,7]$.

\section{Diagnostic Work-Up}

The diagnostic work-up should be aimed at assessing autonomous hormone production and differentiating between benign and (potentially) malignant lesions.

Evaluation of cortisol and (nor)metanephrine secretion should be performed in all patients presenting with an adrenal mass, even in absence of clinical signs of Cushing's syndrome or pheochromocytoma [3, 6, 58, 59]. Also, clinicians should be aware of the possibility of adrenal insufficiency in case of bilateral lesions. Screening for primary hyperaldosteronism by measuring plasma aldosterone concentration and plasma renin activity should be performed if hypertension and/or hypokalemia are present $[6,58]$. The most accurate predictor to differentiate between benign and malignant masses is attenuation on unenhanced CT. If the lesion's attenuation value is $\leq 10$ Hounsfield units (HU), malignancy is extremely unlikely [60]. In case of $\mathrm{HU}>10$, a contrast wash-out sequence should be performed. A washout $>50 \%$ after 15 minutes is indicative of adrenal adenoma. Combined use of attenuation measurement and washout values can be used to discriminate adenomas from other adrenal masses with $98 \%$ sensitivity and $92 \%$ specificity [61].

Percutaneous adrenal biopsy has high false negative rates and there is a risk of complications. Therefore, the only role of percutaneous biopsy in the evaluation of an adrenal mass is confirming metastatic disease in patients with known extraadrenal malignancy and confirming the diagnosis of ACC when radical resection is deemed not possible $[3,58]$.

\section{Remaining Pathologies: A Mixed Group}

There remains a category of lesions that are hormonally inactive and display nonspecific imaging characteristics, which poses a diagnostic challenge. Here we discuss individual entities from this group. A summary of imaging and pathological characteristics of these lesions is provided in Table 1.

Primary adrenal lymphoma (PAL) is a rare finding with less than 200 cases described in the literature. In $70-80 \%$ of cases both adrenal glands are affected [8-11, 62]. On imaging studies, PAL typically presents as a large mass in which cystic or hemorrhagic components may be present.
Homogeneous and heterogeneous lesions are reported in similar frequencies. Diffuse large-cell B cell lymphoma is the most commonly reported subtype, anaplastic large cell or T-cell lymphoma are only reported sporadically [8, 11-13]. Treatment consists of combination chemotherapy, sometimes preceded by surgery in cases of a large tumor mass $[8,14]$. Prognosis depends heavily on treatment response, but a mean overall survival of 15 months has been reported [10, 14].

Liposarcomas account for $45 \%$ of all retroperitoneal soft tissue sarcomas. Five histological subtypes are known, of which well-differentiated liposarcomas (WDLS) and dedifferentiated liposarcomas (DDLS) are most commonly found retroperitoneally [16]. DDLS is found as a focal lesion with low attenuation on T1-weighed MRI within a well-delineated, lipogenic, and septated mass that is the WDLS in approximately $10 \%$ of all cases [17]. Histologically, the dedifferentiated area is characterized by atypical nonlipogenic stromal cells with hyperchromatic nuclei that are scattered in fibrous septa. With increasing grade of dedifferentiation, cellularity increases and nuclear atypia is more prominent. Despite often severe nuclear deformities, the mitotic rate is not very high [18]. Retroperitoneal liposarcomas are notorious for recurring and prognosis is poor: 5-year overall survival rates differ from 36 to $55 \%$ [19-21].

Schwannomas originate from Schwann cells in peripheral nerve sheaths. Approximately 3\% of schwannomas are located in the retroperitoneal space, where it may involve the adrenal gland and/or mimic an adrenal mass [23, 24]. All schwannomas display benign behavior, except for a poorly defined proportion of the rare subtype melanotic schwannoma [25]. The appearance of a schwannoma on CTscan is a round and well-circumscribed mass, hypo- or isointense compared to muscle that enhances after contrast administration [26]. On T1-weighted MRI images, signal intensity is intermediate and similar to muscle. On T2weighted images, signal intensity is markedly increased [26]. Histologically, a schwannoma can be recognized by the presence of elongated spindle cells, organized in areas of both high and low cellularity, called Antoni A and B tissue [24, 26]. Immunohistochemical staining is positive for neuronspecific enolase (NSE), microfilament proteins, and S-100 protein, the neural protein in Schwann cells [24, 27].

To our knowledge, there are no reports on recurrent retroperitoneal schwannoma after radical resection.

Ganglioneuromas typically arise from primordial neural crest cells present in the adrenal medulla [28-30]. Calcifications may be apparent on CT-scan in 30\%-60\% of cases. Unenhanced attenuation values are relatively high: $>25$ HU. Biological behavior is benign in most cases, although malignant transformation is supposedly possible [28].

Idiopathic adrenal haematomas may be discovered as incidentaloma, due to abdominal complaints or due to adrenal insufficiency. Imaging characteristics vary from welldemarcated homogeneous masses to heterogeneous lesions suspect for periadrenal infiltration [33]. Adrenalectomy is often performed in order to obtain a diagnosis.

Adrenal cavernous haemangiomas are very rare and have only been described in individual case reports [36-39]. 


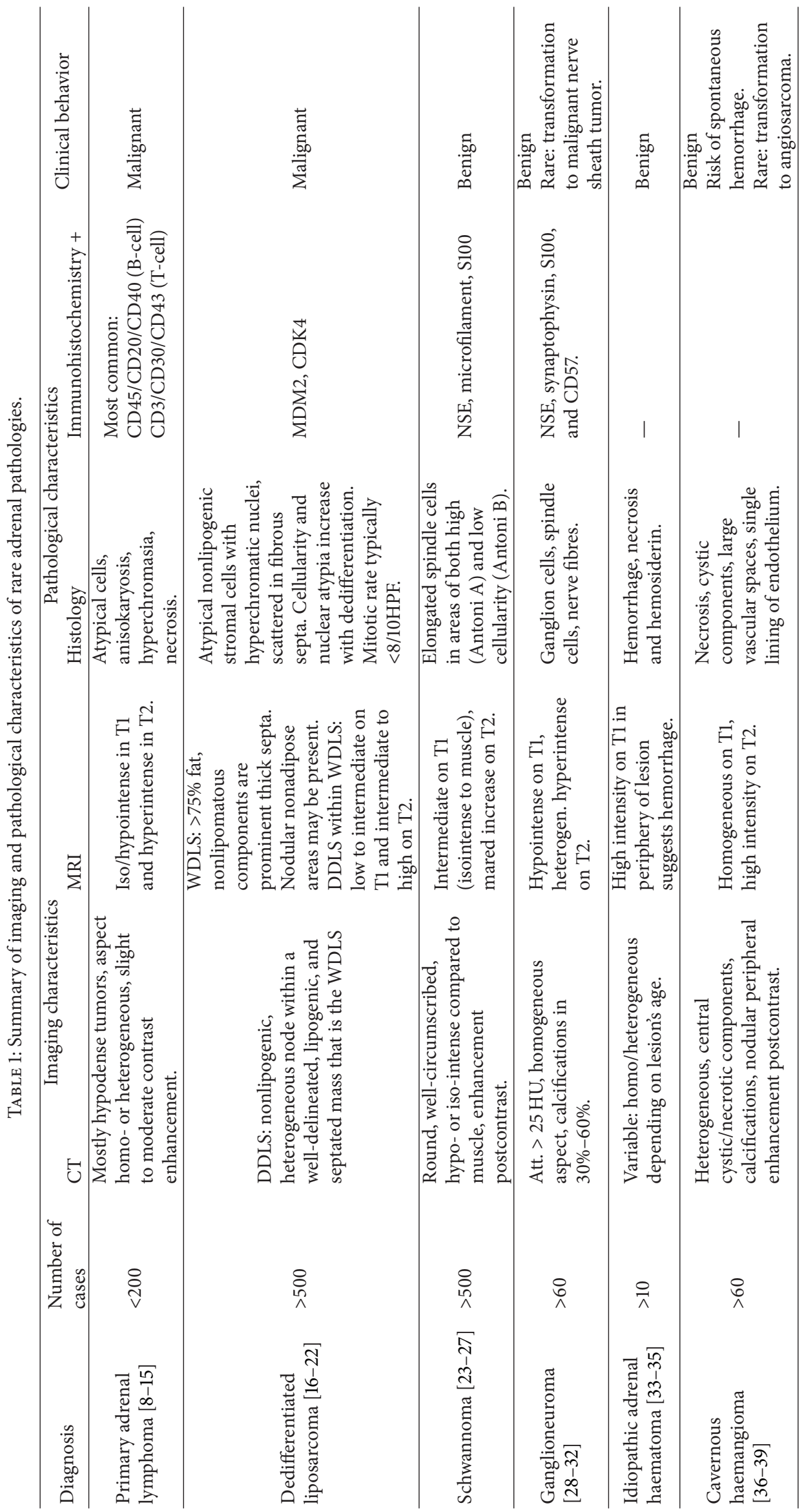




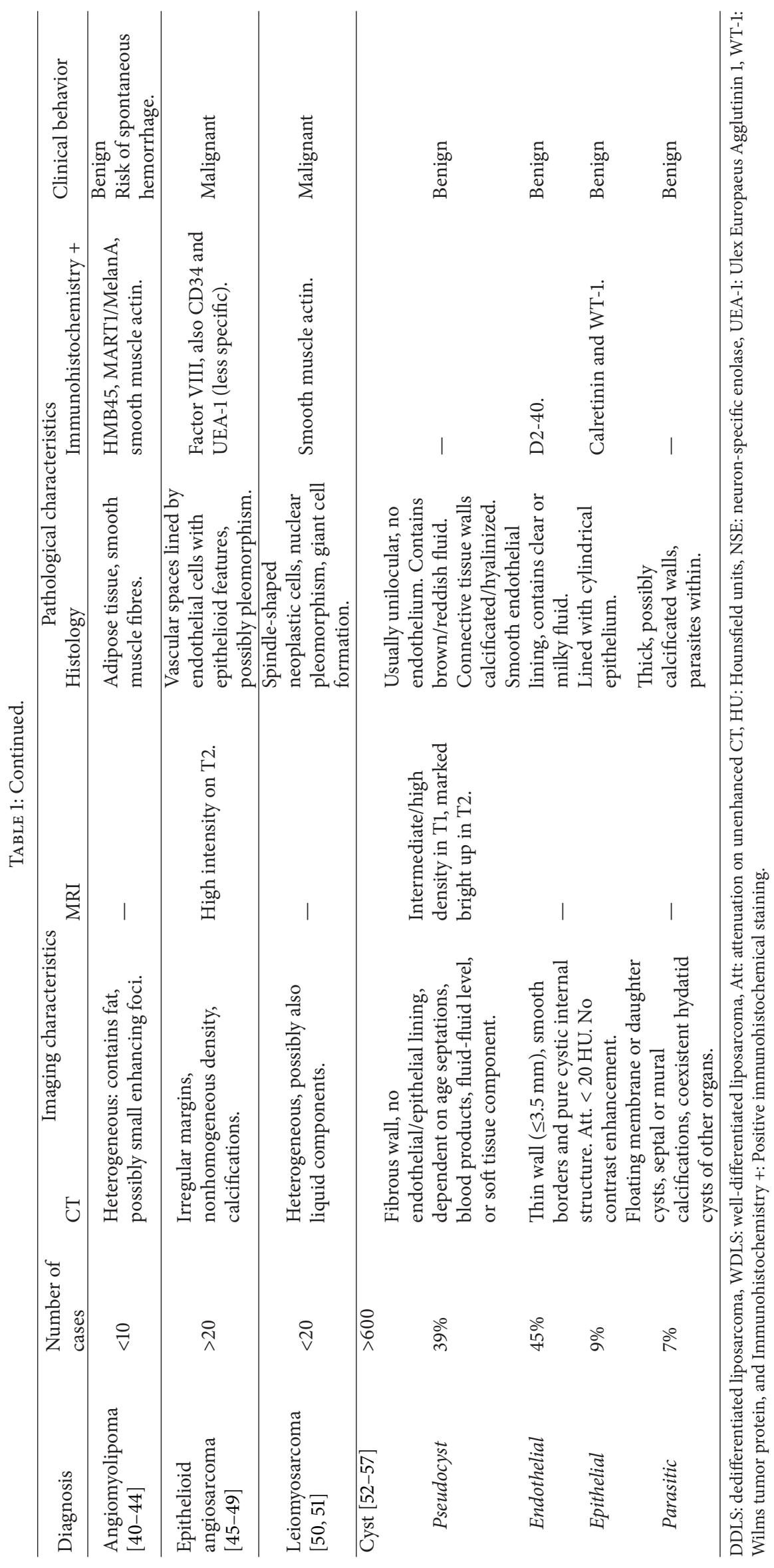


Recurrence after complete resection is not reported; however malignant transformation to angiosarcoma may be possible.

Adrenal angiomyolipomas are extremely rare with only five cases reported [40-44]. These tumors are classified in the family of perivascular epithelioid tumors (so called PEComas). It may be difficult to differentiate this tumor from (ad)renal carcinomas on imaging studies and even upon histological examination. The presence of both adipose tissue and cells positively staining for muscle and melanoma markers are required for definitive diagnosis.

Adrenal leiomyosarcomas and epithelioid angiosarcomas are also exceptionally rare. Concise histomorphological examination combined with positive staining of specific immunohistochemical markers is necessary to confirm the diagnosis $[45,50]$. Invasion of periadrenal tissue and the occurrence of distant metastases are certainly possible, but complete resection in early stage could prevent this from happening [46].

Adrenal cysts form a subcategory which can be divided into pseudocysts, endothelial cysts, epithelial cysts, and parasitic cysts [52]. On CT imaging, differentiation from malignant cystic neoplasms or pseudocysts associated with malignant tumors is not possible [63]. Pseudocysts and endothelial cysts are both considered vascular lesions, the first originating from adrenal hemorrhage and the latter from a preexistent vascular or lymphatic malformation $[53,54]$. Adrenal lymphangioma is a subtype of an endothelial cyst. Histologically, the diagnosis can be established by determining the endothelial origin of the cells through immunohistochemical staining (CD31, CD34, D2-40). Epithelial cysts are more difficult to characterize, as the adrenal gland lacks acini where such a cyst should originate from. An alternative explanation suggests embryonic origin, where the cyst would develop from displaced mesothelial tissue [53]. Parasitic cysts are very rare, mostly caused by infection with echinococcus. However, the adrenal glands are involved in less than $<0.5 \%$ of infected patients [52]. Of note, all adrenal pathologies may display cystic degeneration which should not be confused with these four subtypes of adrenal cysts.

\section{Conclusion}

An adrenal mass may present a diagnostic challenge. If a diagnosis is not established after exclusion of the most common diagnoses, a category remains that consists of rare entities. It may be difficult or even impossible to differentiate between these pathologies based on preoperative diagnostic tests. Radical surgical resection is indicated in case of possibly harmful tumors, for example, lesions with malignant potential, risk of spontaneous hemorrhage, or increase in size over time. Clinicians should assess these issues using clinical judgment complemented with radiological evaluation of the lesion, aimed at characteristics summarized in the present study. This will result in resection of benign lesions, but this is inevitable given the uncertainty that may remain after complete diagnostic work-up. Surgical resection is not necessary if a lesion is judged to be certainly benign unless the size of the lesion causes problems, for example, due to a mass effect on other abdominal organs.

\section{Conflict of Interests}

The authors declare there is no conflict of interests that could be perceived as prejudicing the impartiality of the research reported.

\section{References}

[1] G. Mansmann, J. Lau, E. Balk, M. Rothberg, Y. Miyachi, and S. R. Bornstein, "The clinically inapparent adrenal mass: update in diagnosis and management," Endocrine Reviews, vol. 25, no. 2, pp. 309-340, 2004.

[2] F. Mantero, M. Terzolo, G. Arnaldi et al., "A survey on adrenal incidentaloma in Italy," Journal of Clinical Endocrinology and Metabolism, vol. 85, no. 2, pp. 637-644, 2000.

[3] M. M. Grumbach, B. M. K. Biller, G. D. Braunstein et al., "Management of the clinically inapparent adrenal mass ("incidentaloma”)," Annals of Internal Medicine, vol. 138, no. 5, pp. 424-429, 2003.

[4] W. F. Young Jr., "The incidentally discovered adrenal mass," The New England Journal of Medicine, vol. 356, no. 6, pp. 601-610, 2007.

[5] M. Terzolo, S. Bovio, A. Pia, G. Reimondo, and A. Angeli, "Management of adrenal incidentaloma," Best Practice and Research: Clinical Endocrinology and Metabolism, vol. 23, no. 2, pp. 233-243, 2009.

[6] M. Terzolo, A. Stigliano, I. Chiodini et al., "AME position statement on adrenal incidentaloma," European Journal of Endocrinology, vol. 164, no. 6, pp. 851-870, 2011.

[7] J. Kievit and H. R. Haak, "Diagnosis and treatment of adrenal incidentaloma: a cost-effectiveness analysis," Endocrinology and Metabolism Clinics of North America, vol. 29, no. 1, pp. 69-88, 2000.

[8] A. P. Grigg and J. M. Connors, "Primary adrenal lymphoma," Clinical Lymphoma, vol. 4, no. 3, pp. 154-160, 2003.

[9] A. Ezer, A. Parlakgümüş, N. E. Kocer, T. Çolakoğlu, G. N. Nursal, and S. Yildirim, "Primary adrenal non-Hodgkin's lymphoma: report of two cases," Turkish Journal of Gastroenterology, vol. 22, no. 6, pp. 643-647, 2011.

[10] A. Ozimek, J. Diebold, R. Linke, J. Heyn, K. K. J. Hallfeldt, and T. Mussack, "Bilateral primary adrenal non-hodgkin's lymphoma-a case report and review of the literature," European Journal of Medical Research, vol. 13, no. 5, pp. 221-228, 2008.

[11] A. Ozimek, J. Diebold, R. Linke, J. Heyn, K. Hallfeldt, and T. Mussack, "Bilateral primary adrenal non-Hodgkin's lymphoma and primary adrenocortical carcinoma-review of the literature preoperative differentiation of adrenal tumors," Endocrine Journal, vol. 55, no. 4, pp. 625-638, 2008.

[12] W. L. Frankel, P. Shapiro, and N. Weidner, "Primary anaplastic large cell lymphoma of the adrenal gland," Annals of Diagnostic Pathology, vol. 4, no. 3, pp. 158-164, 2000.

[13] B. Schnitzer, D. Smid, and R. V. Lloyd, "Primary T-cell lymphoma of the adrenal glands with adrenal insufficiency," Human Pathology, vol. 17, no. 6, pp. 634-636, 1986.

[14] R. Kumar, Y. Xiu, A. Mavi, G. El-Haddad, H. Zhuang, and A. Alavi, "FDG-PET imaging in primary bilateral adrenal lymphoma: a case report and review of the literature," Clinical Nuclear Medicine, vol. 30, no. 4, pp. 222-230, 2005.

[15] J. Wang, N. C. Sun, R. Renslo et al., "Clinically silent primary adrenal lymphoma: a case report and review of the literature," 
The American Journal of Hematology, vol. 58, no. 2, pp. 130-136, 1998.

[16] A. M. Crago and S. Singer, "Clinical and molecular approaches to well differentiated and dedifferentiated liposarcoma," Current Opinion in Oncology, vol. 23, no. 4, pp. 373-378, 2011.

[17] M. D. Murphey, L. K. Arcara, and J. Fanburg-Smith, "From the archives of the AFIP: imaging of musculoskeletal liposarcoma with radiologic-pathologic correlation," Radiographics, vol. 25, no. 5, pp. 1371-1395, 2005.

[18] Y. Iwasa and Y. Nakashima, "Dedifferentiated liposarcoma with lipoma-like well-differentiated liposarcoma: clinicopathological study of 30 cases, with particular attention to the comingling pattern of well- and dedifferentiated components: a proposal for regrouping of the present subclassification of well-differentiated liposarcoma and dedifferentiated liposarcoma," International Journal of Surgical Pathology, vol. 21, no. 1, pp. 15-21, 2013.

[19] S. Y. Lee, B. K. P. Goh, M. C. C. Teo et al., "Retroperitoneal liposarcomas: the experience of a tertiary Asian center," World Journal of Surgical Oncology, vol. 9, article 12, 2011.

[20] E. Fabre-Guillevin, J.-M. Coindre, N. de Saint Aubain Somerhausen, F. Bonichon, E. Stoeckle, and N. B. Bui, "Retroperitoneal liposarcomas: follow-up analysis of dedifferentiation after clinicopathologic reexamination of 86 liposarcomas and malignant fibrous histiocytomas," Cancer, vol. 106, no. 12, pp. 2725-2733, 2006.

[21] G. Lahat, D. A. Anaya, X. Wang, D. Tuvin, D. Lev, and R. E. Pollock, "Resectable well-differentiated versus dedifferentiated liposarcomas: two different diseases possibly requiring different treatment approaches," Annals of Surgical Oncology, vol. 15, no. 6, pp. 1585-1593, 2008.

[22] K. Y. Lam and C. Y. Lo, "Adrenal lipomatous tumours: a 30 year clinicopathological experience at a single institution," Journal of Clinical Pathology, vol. 54, no. 9, pp. 707-712, 2001.

[23] T. Inokuchi, H. Takiuchi, Y. Moriwaki et al., "Retroperitoneal ancient schwannoma presenting as an adrenal incidentaloma: CT and MR findings," Magnetic Resonance Imaging, vol. 24, no. 10, pp. 1389-1393, 2006.

[24] T. Theodosopoulos, V. K. Stafyla, P. Tsiantoula et al., "Special problems encountering surgical management of large retroperitoneal schwannomas," World Journal of Surgical Oncology, vol. 6, article 107, 2008.

[25] D. M. Skovronsky and J. C. Oberholtzer, "Pathologic classification of peripheral nerve tumors," Neurosurgery Clinics of North America, vol. 15, no. 2, pp. 157-166, 2004.

[26] M. Pilavaki, D. Chourmouzi, A. Kiziridou, A. Skordalaki, T. Zarampoukas, and A. Drevelengas, "Imaging of peripheral nerve sheath tumors with pathologic correlation: pictorial review," European Journal of Radiology, vol. 52, no. 3, pp. 229239, 2004.

[27] M. Giglio, V. Giasotto, M. Medica et al., "Retroperitoneal ancient schwannoma: case report and analysis of clinicoradiological findings," Annales d'Urologie, vol. 36, no. 2, pp. 104106, 2002.

[28] H. Shawa, K. M. Elsayes, S. Javadi et al., "Adrenal ganglioneuroma: features and outcomes of 27 cases at a referral cancer centre," Clinical Endocrinology, vol. 80, no. 3, pp. 342-347, 2014.

[29] G. Rondeau, S. Nolet, M. Latour et al., "Clinical and biochemical features of seven adult adrenal ganglioneuromas," Journal of Clinical Endocrinology and Metabolism, vol. 95, no. 7, pp. 3118$3125,2010$.
[30] D. Linos, T. Tsirlis, A. Kapralou, A. Kiriakopoulos, D. Tsakayannis, and D. Papaioannou, "Adrenal ganglioneuromas: incidentalomas with misleading clinical and imaging features," Surgery, vol. 149, no. 1, pp. 99-105, 2011.

[31] C. L. Chen, S. T. Huang, P. L. Chang, and K. F. Ng, "Adrenal ganglioneuroma: report of five cases," Chang Gung Medical Journal, vol. 23, no. 9, pp. 550-554, 2000.

[32] Y. Qing, X. Bin, W. Jian et al., "Adrenal ganglioneuromas: a 10year experience in a Chinese population," Surgery, vol. 147, no. 6, pp. 854-860, 2010.

[33] C. Vincent, J. B. Brewster, V. Kedar, and C. P. Sundaram, "Unilateral idiopathic adrenal hematomas with a preoperative diagnosis of indeterminate adrenal tumors," Journal of Endourology, vol. 22, no. 5, pp. 995-997, 2008.

[34] H. Imachi, K. Murao, T. Yoshimoto et al., "Idiopathic unilateral adrenal hemorrhage in an elderly patient," Endocrine, vol. 37, no. 2, pp. 249-252, 2010.

[35] K. Sasaki, T. Yamada, K. Gotoh et al., "Idiopathic adrenal hematoma masquerading as neoplasm," Case Reports in Gastroenterology, vol. 6, no. 1, pp. 171-176, 2012.

[36] N. Galea, V. Noce, F. Ciolina, S. Liberali, and M. Francone, "Giant adrenal cavernous hemangioma: a rare abdominal mass," Urology, vol. 82, no. 1, pp. e3-e4, 2013.

[37] A. J. Kieger, P. Nikolaidis, and D. D. Casalino, "Adrenal gland hemangioma," Journal of Urology, vol. 186, no. 6, pp. 2415-2416, 2011.

[38] S. D. Quildrian, E. A. Silberman, F. A. Vigovich, and E. A. Porto, "Giant cavernous hemangioma of the adrenal gland," International Journal of Surgery Case Reports, vol. 4, no. 2, pp. 219-221, 2013.

[39] D. A. Telem, S. Q. Nguyen, E. H. Chin, K. Weber, and C. M. Divino, "Laparoscopic resection of giant adrenal cavernous hemangioma," Journal of the Society of Laparoendoscopic Surgeons, vol. 13, no. 2, pp. 260-262, 2009.

[40] A. D'Antonio, A. Caleo, O. Caleo, G. de Dominicis, and A. Boscaino, "Monotypic epithelioid angiomyolipoma of the adrenal gland: an unusual site for a rare extrarenal tumor," Annals of Diagnostic Pathology, vol. 13, no. 5, pp. 347-350, 2009.

[41] R. Godara, M. G. Vashist, S. L. Singla et al., "Adrenal angiomyolipoma: a rare entity," Indian Journal of Urology, vol. 23, no. 3, pp. 319-320, 2007.

[42] H. Hu and X. Xi, "Giant adrenal angiomyolipoma," Journal of Clinical Endocrinology and Metabolism, vol. 97, no. 11, pp. 38353836, 2012.

[43] R. Sutter, A. Boehler, and J. K. Willmann, "Adrenal angiomyolipoma in lymphangioleiomyomatosis," European Radiology, vol. 17, no. 2, pp. 565-566, 2007.

[44] O. Yener and A. Ozcelik, "Angiomyolipoma of the right adrenal gland," ISRN Surgery, vol. 2011, Article ID 102743, 2 pages, 2011.

[45] E. Pasqual, F. Bertolissi, F. Grimaldi et al., "Adrenal angiosarcoma: report of a case," Surgery Today, vol. 32, no. 6, pp. 563$565,2002$.

[46] A. G. Croitoru, A. P. Klausner, G. McWilliams, and P. D. Unger, "Primary epithelioid angiosarcoma of the adrenal gland," Annals of Diagnostic Pathology, vol. 5, no. 5, pp. 300-303, 2001.

[47] B. M. Wenig, S. L. Abbondanzo, and C. S. Heffess, "Epithelioid angiosarcoma of the adrenal glands: a clinicopathologic study of nine cases with a discussion of the implications of finding 'epithelial- specific' markers," The American Journal of Surgical Pathology, vol. 18, no. 1, pp. 62-73, 1994. 
[48] G. Gambino, T. Mannone, A. Rizzo et al., "Adrenal epithelioid angiosarcoma: a case report," Chirurgia Italiana, vol. 60 , no. 3 , pp. 463-467, 2008.

[49] J. Hart and S. Mandavilli, "Epithelioid angiosarcoma: a brief diagnostic review and differential diagnosis," Archives of Pathology and Laboratory Medicine, vol. 135, no. 2, pp. 268-272, 2011.

[50] S. D. Deshmukh, S. V. Babanagare, M. Anand, D. P. Pande, and P. Yavalkar, "Primary adrenal leiomyosarcoma: a case report with immunohistochemical study and review of literature," Journal of Cancer Research and Therapeutics, vol. 9, no. 1, pp. 114-116, 2013.

[51] S. Hamada, K. Ito, M. Tobe et al., "Bilateral adrenal leiomyosarcoma treated with multiple local therapies," International Journal of Clinical Oncology, vol. 14, no. 4, pp. 356-360, 2009.

[52] D. G. Foster, "Adrenal cysts. Review of literature and report of case," Archives of Surgery, vol. 92, no. 1, pp. 131-143, 1966.

[53] A. Wedmid and M. Palese, "Diagnosis and treatment of the adrenal cyst," Current Urology Reports, vol. 11, no. 1, pp. 44-50, 2010.

[54] C. Sebastiano, X. Zhao, F.-M. Deng, and K. Das, "Cystic lesions of the adrenal gland: our experience over the last 20 years," Human Pathology, vol. 44, no. 9, pp. 1797-1803, 2013.

[55] H.-P. Chien, Y.-S. Chang, P.-S. Hsu et al., "Adrenal cystic lesions: a clinicopathological analysis of 25 cases with proposed histogenesis and review of the literature," Endocrine Pathology, vol. 19, no. 4, pp. 274-281, 2008.

[56] H. T. Sanal, M. Kocaoglu, D. Yildirim et al., "Imaging features of benign adrenal cysts," European Journal of Radiology, vol. 60, no. 3, pp. 465-469, 2006.

[57] J. Suh, A. Heimann, and H. Cohen, "True adrenal mesothelial cyst in a patient with flank pain and hematuria: a case report," Endocrine Pathology, vol. 19, no. 3, pp. 203-205, 2008.

[58] J. G. Bittner IV and L. M. Brunt, "Evaluation and management of adrenal incidentaloma," Journal of Surgical Oncology, vol. 106, no. 5, pp. 557-564, 2012.

[59] L. K. Nieman, "Approach to the patient with an adrenal incidentaloma," The Journal of Clinical Endocrinology \& Metabolism, vol. 95, no. 9, pp. 4106-4113, 2010.

[60] A. H. Hamrahian, A. G. Ioachimescu, E. M. Remer et al., "Clinical utility of noncontrast computed tomography attenuation value (hounsfield units) to differentiate adrenal adenomas/hyperplasias from nonadenomas: cleveland clinic experience," The Journal of Clinical Endocrinology and Metabolism, vol. 90, no. 2, pp. 871-877, 2005.

[61] I. I. Androulakis, G. Kaltsas, G. Piaditis, and A. B. Grossman, "The clinical significance of adrenal incidentalomas," European Journal of Clinical Investigation, vol. 41, no. 5, pp. 552-560, 2011.

[62] A. Rashidi and S. I. Fisher, "Primary adrenal lymphoma: A systematic review," Annals of Hematology, vol. 92, no. 12, pp. 1583-1593, 2013.

[63] J. M. Longo, S. Z. Jafri, and K. B. Bis, "Adrenal lymphangioma: a case report," Clinical Imaging, vol. 24, no. 2, pp. 104-106, 2000. 


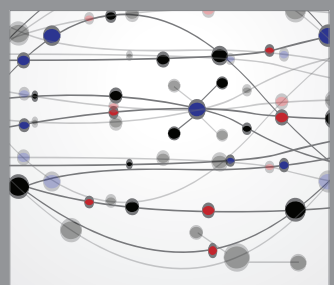

The Scientific World Journal
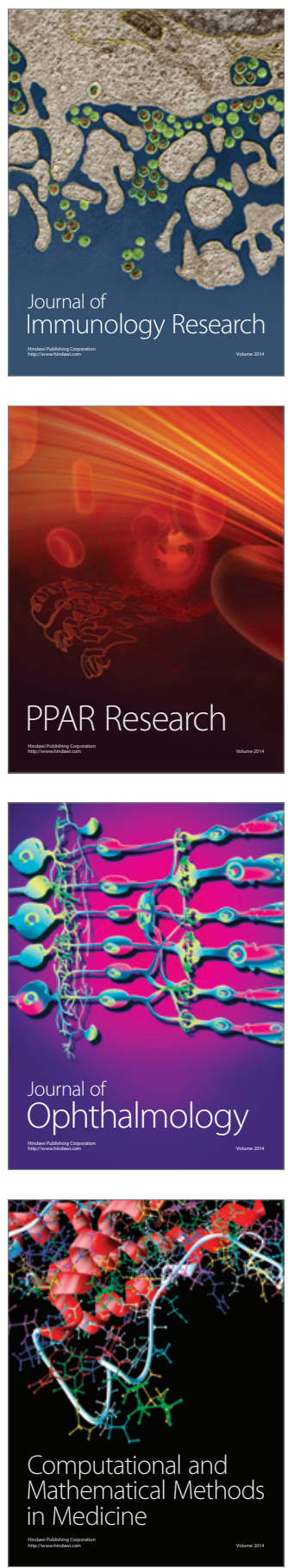

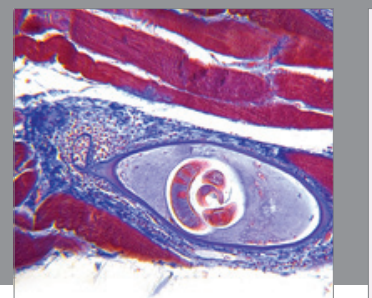

Gastroenterology

Research and Practice
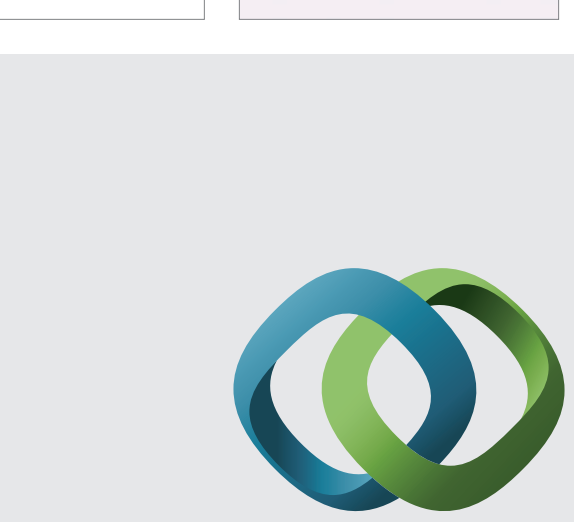

\section{Hindawi}

Submit your manuscripts at

http://www.hindawi.com

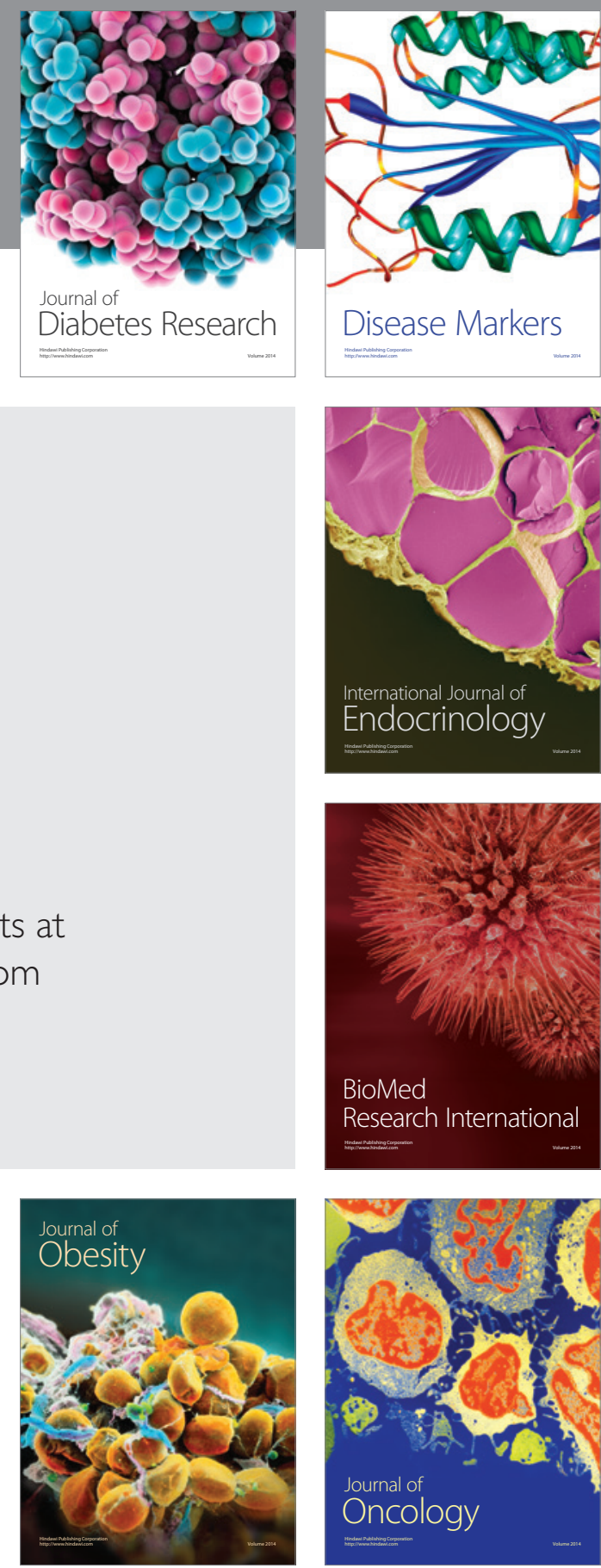

Disease Markers
